\title{
The Need for an Analysis Body of Knowledge (ABOK) - Will the Real Analyst Please Stand Up?
}

\author{
Nina Evans \\ Tshwane University of Technology, South Africa
}

\author{
evansa@tut.ac.za
}

\begin{abstract}
An in-depth study of the business-IT interface produced numerous reasons why Information Technology (IT) solutions often do not meet the expectations of the business client. Major contributors towards the expectation gap are: Insufficient analysis of the business problem, bad user requirement specifications and documentation, ineffective communication and interpersonal relationship problems. All of these are the responsibility of the business- and/or systems analyst, who acts as a bridge between the IT function and the rest of the business.

There is confusion about the title, role and required knowledge and skills of analysts. A formal 'Body of Knowledge' (BOK) can address the confusion in the ICT industry and guide higher education institutions to effectively prepare such employees for the industry. This article discusses the results of the initial phase of a joint research project by the Tshwane University of Technology and the Special Interest Group for Analysis in South Africa towards creating such an Analysis Body of Knowledge (ABOK). In this phase the need for a BOK was determined and the world of analysis in South Africa investigated to draw up a preliminary analysis profile. The plans for follow-up research to develop a comprehensive ABOK are also discussed.
\end{abstract}

Keywords: Information and Communications Technology (ICT), analyst, business analysis, systems analysis, Body of Knowledge (BOK)

\section{Introduction}

A number of research projects have been completed throughout the world to quantify the success rate of IT projects and it was found that the percentage of unsuccessful information systems in organisations is very high. The criteria for success of IT projects are that they are delivered on time, within (or below) the budget, that the systems work with no interruptions or 'bugs' and that the systems meet the client/business user expectations. Failures include extended schedules, exceeding the budget and failing to meet stakeholder needs. According to the Standish group's CHAOS report of $2000,26 \%$ of software projects succeed, which means that $74 \%$ fail.

In the past, traditional job titles for IT workers, such as programmer and systems analyst defined where people fit in the IT world. Currently those titles are less important; skills and experience

Material published as part of this journal, either on-line or in print, is copyrighted by Informing Science. Permission to make digital or paper copy of part or all of these works for personal or classroom use is granted without fee provided that the copies are not made or distributed for profit or commercial advantage AND that copies 1) bear this notice in full and 2) give the full citation on the first page. It is permissible to abstract these works so long as credit is given. To copy in all other cases or to republish or to post on a server or to redistribute to lists requires specific permission from the publisher at Publisher@InformingScience.org seem to be more important than titles in determining rank and pay. Alexander (1999) supports this in saying that even the definitions of IT job titles, such as programmer, programmer analyst, systems analyst and project manager, are "fuzzy". A programmer may be called a software engineer, software developer, or an application de- 
veloper. A programmer analyst can be called a senior programmer or a senior developer. There is often no distinction between a systems analyst and a programmer analyst." Even the hierarchy of IT job titles is breaking down. For example, one version of the IT hierarchy lists these jobs in ascending order: Programmer analyst, senior systems programmer, senior systems analyst, project manager, network administrator and computer operations manager. But, according to Alexander (1999) pay doesn't necessarily go in that order anymore and "a project manager's authority varies widely from one company to another."

Some companies create their own titles, adding to the title confusion - titles are likely to become more confusing in the future. According to Alexander (1999) 'business analyst' is one of the least well-defined IT titles. It can mean a technical person with some business expertise, or a businessperson with some technical skills. The business analyst is a "squishy job title", but it is important and these people are hard to come by. "There are technical people who know bits and bytes but can't speak in end-user terms, and there are business people who lack enough technical expertise to make things happen in IT."

Many organisations have a role called business analyst, sometimes combined with the role of systems analyst. The combination of business- and systems analysis is sometimes referred to as business systems analysis. There doesn't seem to be any standard definition of what a business analyst or a systems analyst is and what they should be doing, although every organisation seems to have them. In the modern view of business analysis, it consists of the specification of business requirements, followed by the specification of the technical requirements and designs.

According to the B2T Training group (www.b2ttraining.com) business analysis is one of the most fundamental and challenging information technology positions: "Analysis moves a project from its initial state of uncertainty to a clearly defined and agreed upon set of requirements, through to an information system, which would solve the business problems". A business analyst usually specialises in business problem analysis and technology-independent requirements analysis. They are typically recruited from the user community and therefore they focus on business and non-technical aspects of systems problems solving. Their job is to identify, document and validate requirements and to identify ways or areas to add value to the organisation. A critical skill of the Business Analyst is the ability to investigate and understand how a business is actually run, as opposed to how developers think it works or want it to work. They often also "pair-program" with one of the developers on code or work with users on developing acceptance tests. Systems analysts are more involved in the technical aspects of information systems. They are involved in the design of the system and are responsible for the technical specifications.

Once the analysis is completed, the analyst must communicate the results to the programmers who will code and implement the solution. Analysts therefore need to communicate business needs to information technology specialists. They facilitate the liaison between business people who have a business problem and technology people who know how to create automated solutions, throughout the entire development and installation process. Analysts are key to ensuring a good fit between the information system and the organization. Their role is integral to the success of the information system and, in turn, the success of the organisation.

Analysts must therefore have abilities in two major areas:

First, they must be able to deal with users. This means analysts should have good interpersonal skills, be able to communicate, and have knowledge of the user's functional area. A key role of the analyst is to identify and reconcile the practical- and people problems that arise in IT projects. For the first time, 'soft skills' like stress management and personal growth are on the corporate agenda. It seems that companies offer people with substantial soft skills, but minimal technical skills, the same opportunities as those with good technical skills. 
Second, analysts should have sufficient technical knowledge so that they can understand the capabilities of computers and are able to gather and interpret facts. People with both technical skills and soft skills enjoy unlimited opportunities in the modern organisation.

\section{The Research}

\section{Rationale and Motivation for the Research}

The IT function within organisations often fails to meet the expectations of the business client, as IT solutions do not solve the real business problem. Business- and/or systems analysts are responsible for the business and technical analysis and design of the business solution and to manage the soft issues arising from the relationship. The analyst therefore has an important role in bridging the gap, but an investigation into the world of the analyst indicated a lot of confusion concerning their role and responsibilities. A formal Body of Knowledge for analysis might contribute towards alleviating this confusion.

A central element of Higher Education institutions meeting the needs of the ICT industry is the promotion of links with this industry to enhance the skills and abilities of graduates. Learners can only make the right career decision if they are informed about the characteristics of the ICT industry and the skills expected of employees within this industry. It is imperative that lecturing staff becomes involved in determining the various career options in the ICT industry and the characteristics of each. If the required profile of analysts is captured in an Analysis Body of Knowledge (ABOK), the course structures and module contents can be designed accordingly.

\section{The Purpose of the Research}

The purpose of the research was to determine the need for an Analysis Body of Knowledge $(\mathrm{ABOK})$ and to investigate the world of business- and/or systems analysis as a starting point towards such an Analysis Body of Knowledge (ABOK).

\section{Research Methodology}

Since the general shift in IS/IT research, away from technological issues to managerial and organisational issues, there has been an increasing interest in qualitative research in this field. The motivation for doing qualitative research comes from the observation that, if there is one thing that distinguishes humans from the natural world, it is their ability to talk. Qualitative research methods are designed to help researchers communicate with- and to "understand people and the social and cultural context within which they live" (Meyers, 2002). Although most researchers do either quantitative or qualitative research, they were combined in this project. The combination of independent, yet complementary research methods is called triangulation (also referred to as "mixed methods"). The benefits of triangulation are that the methods complement each other and the inadequacies of individual methods are minimised.

\section{The Research Design}

In the preliminary part of the research, 191 reasons for the "expectation gap" between business clients and the IT function were determined from literature and the related issues were classified into 25 categories. Business managers, IT managers and employees responsible for business and/or systems analysis were then asked to rank the various issues according to significance. A number of the most important categories can be directly linked to the job of the analyst, namely :

- Lack of Communication between IT- and business

- Project scope changes (changing business needs / technology) 
- The real business need is not understood and solved (ineffective requirements specification)

- There seems to be problems in the analysis phase of system development and a BOK might be an important step in solving these problems.

Next, the knowledge, skills (technical and non-technical) and personal attributes required of business- and systems analysts were determined by a content analysis of job advertisements, job descriptions and training programs from various institutions. The results of the content analysis were then used to design a questionnaire for determining which of these skills are actually used by practicing analysts. The questionnaire was published on the Internet and analysts were invited to participate in the survey. This was followed by personal interviews and a focus group session, with the specific purpose of determining the people issues (organisational behaviour issues) faced by analysts. The results of the research can be used as the starting point of an Analysis Body of Knowledge.

\section{Results: The World of Analysis}

\section{Demographic Data of the Respondents}

There were 79 usable responses to the online questionnaire, which translates to approximately $10 \%$ of the total number of people who were invited to participate. The respondents are employed at 37 different companies in South Africa. On average they have 4 years of experience in their current jobs. The respondents' previous experience includes project management, programming, business management, technical support, statistics, sales management and data architecture.

Their current job titles vary significantly, supporting the literature that there are no clear-cut titles for analysts in organisations. Respondents were asked to indicate whether they are mainly responsible for business analysis (BA), systems analysis (SA) or both business- and systems analysis (BSA) (Table 1) and whether they are employed in the IT department or business function of their organization (Table 2). Due to possible job title confusion the questions in the questionnaire did not refer to the titles of employees (e.g. business analyst and programmer analyst), but rather to the responsibility for business- or systems analysis.

\begin{tabular}{|l|l|}
\hline \multicolumn{2}{|c|}{ Table 1. Demographic data of the respondents } \\
\hline Major responsibility & $\%$ of respondents \\
\hline Business analysis & 40 \\
\hline Systems analysis & 9 \\
\hline Both business- and systems analysis (BASA) & 42 \\
\hline Other & 9 \\
\hline
\end{tabular}


Table 2: Host departments of the respondents

\begin{tabular}{|l|l|l|l|}
\hline Department & IT department & Business department & Independent consultants \\
\hline BA & $56 \%$ & $34 \%$ & $10 \%$ \\
\hline SA & $71 \%$ & - & $29 \%$ \\
\hline BASA & $72 \%$ & $6 \%$ & $22 \%$ \\
\hline
\end{tabular}

The variation in job titles associated within each of these categories of responsibilities can be seen in appendix 1 (duplicates removed). It is noteworthy that some employees with the job title systems analyst or business analyst are responsible for both business- and systems analysis and that one respondent who calls himself a business analyst, regards the main responsibility of his job to be systems analysis.

The academic qualifications of the respondents were remarkably high. $63 \%$ of the respondents have a tertiary qualification; the majority $(50 \%)$ of the respondents have degrees and higher degrees, whereas $13 \%$ completed a national Diploma. Only $13 \%$ have no tertiary qualification at all.

The majority of the respondents received training in IT skills (89\%), while a high percentage $(66 \%)$ were also trained in business skills. A large percentage of respondents received training in interpersonal skills (59\%). This is probably an indication that business- and interpersonal skills are especially important for analysts.

\section{The Relevance and Format of the Survey}

The participants were invited to comment on the relevance of a survey of this nature and the format and design of the questionnaire. The comments made by participants, are a clear indication of the importance and timely nature of this research project. The opinion of most of the respondents on the research initiative is reflected by the words of one person: "I think a survey of this sort is long overdue. Organisations very often do not fully grasp the importance of the analysis phase of a project. The need to plan more effectively and efficiently up front to ensure a successful implementation is not understood. Consequently, development is often done with insufficient analysis resulting in frequent rework and fire-fighting. Both IT and Business need to understand where analysis fits into the SDLC."

The comments made by the respondents on the survey in general were very positive. Some of these comments were:

"Well thought out."

“Absolutely essential!!!!!!!!!!! Thanks!”

“About time! :-)”

"I think this survey is an excellent method to gather information on the perceptions of business analysts and to become aware of the kind of people and skills available."

"Seems to be very relevant questions, and good that one can add comments along the way. I'm keen to see the results of this survey."

"Excellent layout, looking forward to results."

"It's brilliantly formulated, well done to the group that put it together." 
Need for an Analysis Body of Knowledge

"This is a very 'grey' area and we NEED the help we get. I really think that this is a great initiative. Please press this issue and make it work."

"Interesting research topic, would like to see results. Thanks."

"Curious to see the outcome and the way forward. Good luck!"

"Good survey......be interesting to see what the outcome is."

The only two negative comments received on the survey were: "The online questionnaire took a bit longer than was envisaged (40 minutes) - the site was quite slow" and "The survey is a good start, but not exhaustive."

\section{The Need for a Professional Body and Body of Knowledge}

There was an overwhelming support for a professional body and professional status for businessand systems analysts. $92 \%$ of the respondents were in favour a professional body for analysts in South Africa. All the respondents (100\%) regarded a body of knowledge (BOK) as important. One respondent commented: "It would be great if in future there could be something like an Analysis Competency and to actually do a 'pro-metric' type 'certification' for analysts. It would also be nice to have an overall 'best practice' model that has actual problems and solutions in South Africa." Another said: "It is imperative that a body of knowledge regarding Business Analysis is developed. A clear distinction must be made between Business Analysis (analysis) and System Analysis (design). This distinction is often not well understood and is the heart of system solution problems. Business role players must first understand their business events and how they want their business to operate (including the Business Rules), before specifying the System and People solutions for how to support it." Another respondent agreed that a body of knowledge is essential, but had a different opinion of the distinction between business- and systems analysis: "People define their roles differently but essentially we perform similar functions. I would love a standardisation of role definition. I would also love a central base of sharing knowledge across industries as well as tailor made training initiatives specific to the roles."

\section{What analysts do}

A number of questions were asked to determine the viewpoints of analysts on different matters. The responses are shown in Table 3:

\begin{tabular}{|c|c|c|}
\hline \multicolumn{3}{|c|}{ Table 3: Responses to questions on viewpoints } \\
\hline \multicolumn{3}{|c|}{ Do you need an IT background to do your current job? } \\
\hline & Essential & Useful but not essential \\
\hline BA & $39 \%$ & $61 \%$ \\
\hline SA & $57 \%$ & $43 \%$ \\
\hline BASA & $70 \%$ & $30 \%$ \\
\hline \multicolumn{3}{|c|}{$\begin{array}{l}\text { Do you apply business knowledge to increase the effectiveness of com- } \\
\text { puter systems? }\end{array}$} \\
\hline & Very often & Often \\
\hline BA & $56 \%$ & $44 \%$ \\
\hline
\end{tabular}




\begin{tabular}{|c|c|c|c|}
\hline SA & $43 \%$ & \multicolumn{2}{|l|}{$57 \%$} \\
\hline BASA & $70 \%$ & \multicolumn{2}{|l|}{$18 \%$} \\
\hline \multicolumn{4}{|c|}{$\begin{array}{l}\text { Do you act as a liaison between business people who have a business } \\
\text { situation and technology people who provide IT solutions? }\end{array}$} \\
\hline & Very often & & \\
\hline $\mathbf{B A}$ & $78 \%$ & & \\
\hline SA & $43 \%$ & & \\
\hline BASA & 645 & & \\
\hline \multicolumn{4}{|c|}{ Are you directly involved in software development? } \\
\hline & Very often and often & Seldom & Never \\
\hline BA & $31 \%$ & $47 \%$ & $19 \%$ \\
\hline SA & $86 \%$ & $0 \%$ & $14 \%$ \\
\hline BASA & $67 \%$ & & \\
\hline \multicolumn{4}{|c|}{ Are you responsible for producing technical requirement specifications? } \\
\hline & Very often and Often & \multicolumn{2}{|c|}{ Seldom and Never } \\
\hline BA & $34 \%$ & \multicolumn{2}{|l|}{$66 \%$} \\
\hline SA & $58 \%$ & \multicolumn{2}{|l|}{$42 \%$} \\
\hline BASA & $60 \%$ & \multicolumn{2}{|l|}{$40 \%$} \\
\hline
\end{tabular}

Do you analyze the business requirements before specifying a system (i.e. a customised solution or existing package)?

\begin{tabular}{|l|l|l|l|l|}
\hline & \% All & \% BA & \% SA & \%BASA \\
\hline Always & 65 & 59 & 57 & 70 \\
\hline Most of the time & 24 & 25 & 15 & 30 \\
\hline Don't know & 0 & 0 & 0 & 0 \\
\hline Seldom & 8 & 16 & 14 & 0 \\
\hline Never & 3 & 0 & 14 & 0 \\
\hline
\end{tabular}

Do you consider yourself to be a technical expert with some business knowledge or a business expert with some technical skills?

Respondents who are responsible for business analysis mostly regard themselves as business experts with some technical skills. Those who do systems analysis mostly regard themselves as 
technical experts with some business knowledge. The people who are responsible for both types of analysis were split halfway between these two options (51\% versus $49 \%)$.

Do you think there is a need for academic training of students in a combination of IT skills, business skills and interpersonal skills?

There is definitely a need for academic training of students in the skills mentioned. $68 \%$ of the respondents strongly agreed and $28 \%$ agreed that this is necessary. Only $1 \%$ of the respondents regarded such training as unimportant. $72 \%$ of the systems analysts and $59 \%$ of the business analysts strongly agreed that academic training is important. This is probably because the business skills needed by business analysts are easier to learn on the job. $76 \%$ of the people who do both business and systems analysis strongly agreed to the need for academic training. This emphasises the need for an instructional offering that includes both business- and technical IT skills.

The response to this question varied according to the academic qualifications of the respondents. No respondent strongly disagreed that there is a need for academic qualifications. The only respondents who disagreed that there is a need for formal qualifications were people with only matric $(10 \%)$. The higher the qualifications of the respondents, the more strongly they agreed to the need for such qualifications. $70 \%$ of diplomats, $76 \%$ of graduates, $86 \%$ of the people with honours degrees and $100 \%$ of those with Masters and Doctorate degrees strongly agreed that there is a need for academic training in analysis.

\section{The Professional Profile of Analysts}

\section{Responsibilities of analysts}

Comments made by respondents indicate that the roles and responsibilities of analysts are not a clear-cut case. One respondent said: "I think there is a huge gap between business and IT and this is what I see as the responsibility of a Business Analysis; to provide a link between business and IT, thus talking both languages. I don't believe the system-and business analyst should be the same person. These are two areas of speciality and I don't know many people who can fill both these roles." Another respondent differed from this viewpoint and said: "I feel the two career positions should be merged into one position for analysts who have both technical hands on and with business knowledge. Sometimes there is a duplication of tasks, especially when doing investigations one's specification can contain the design and requirements. Executives want to hear this from one person."

Six responsibilities were selected amongst the top ten choices by all three groups of respondents. These are therefore important for both business and systems analysis and are included in the middle of the figure below. The responsibilities at the top and bottom indicate the unique responsibilities of business analysis and systems analysis respectively. 
Design new business administration processes

User acceptance testing

Use cases

System implementation (Business usage / administration)

Extract and document user requirements

Identify needs for new information systems and/or technology

Evaluate different solutions

Analyse/record existing business administration processes

Determine the impact of new systems on the business Activity diagrams

Documentation of Computer Systems

Testing (IT Development)

System implementation (Hardware/software)

Install, maintain and administer existing com-
Business analysis

Both business and

systems analysis

Systems analysis

The responsibilities that were added in the 'other' section of the questionnaire, is shown in Appendix 2.

\section{The concepts/techniques used in the job}

Six of the concepts were amongst the top ten choices of all the respondents and they are therefore important for both business and systems analysis. 
Business process management

Decomposition and partitioning of the processes

Business analysis

Narrative text

Use case

Process flow charts / swim lanes

Value chains / end-to-end processes

Documentation of each task in detail with data, controls and business rules

Entity relationship diagram / logical data model

Both business and systems analysis

Functional decomposition

Business event data flow diagrams

Decomposition and partitioning of the processes

Converting analysis models to design models

\title{
Systems analysis
}

Self-developed design techniques

\section{Technical (IT related) skills used in the job}

Four of the technical skills were amongst the top ten choices of all the analysts and are therefore important for business analysis, systems analysis and business systems analysis. The technical skills used and the average of the rankings are as follows:

\author{
CASE tools \\ RUP (Rational Unified Process) \\ UML \\ ERP Software \\ Visual Basic \\ MS Office \\ MS Project \\ Data modelling tools \\ SQL \\ Visual Basic \\ HTML \\ ERP Software \\ Java \\ MS Query \\ MS FrontPage
}

Systems analysis

Business analysis

Both business- and systems analysis 
One interviewee commented: "Mastering new languages, new software and hardware should be a continuous challenge."

\section{Knowledge of principles applied in the job}

Eight of the principles were amongst the top ten choices of all the analysts and are therefore important for business analysis, systems analysis and business systems analysis.

Change management

Financial management

Relational database

Data modelling

Software lifecycle (SDLC)

Database management

Quality management

Object oriented analysis/development

Strategic thinking

Risk assessment

Client server

Data Warehousing
Business analysis

Both business- and systems analysis

Systems analysis

\section{Non-technical skills}

The ability to work well with people

Research skills

Analytical skills

Business sense

Detailed problem solving

Written communication skills

Listening skills

Teamwork and-leadership

Oral communication skills

Multitasking
Business analysis

Both business- and systems analysis

Systems analysis

It is clear that the combination of analytical skills, business sense and communication skills are extremely important in analysis. An interviewee elaborated on analytical skills: "You will need to understand your customers and the markets. Research design and analytical skills are critical - 
Need for an Analysis Body of Knowledge

e.g. conducting market research studies, using database- and statistical packages. Training in measurement and statistics is desirable."

Business sense is important for analysts. In an interview, one participant said: "Analysts should be focused on influencing business decisions that impact the sales forecast. They will determine where the inefficiencies are and make recommendations to improve the profitability of the business." Business sense was selected as one of the top five skills for systems analysis too, although the emphasis is usually more on technical skills. During an interview a systems analyst commented: "Analysts need to have a sense of what it takes to run a successful business. Profitability is important and you should know what it means to increase revenues and manage costs. Training in management accounting and activity based costing is desirable." This is supported by the B2B training group (www.b2btraining.com) who are responsible for training analysts: "Business problems do not come as neatly packaged as marketing problems, accounting problems or organizational problems. They arise within the context of the business, with all the complexity and richness that a business provides."

Written communication skills are important for all analysts. Oral communication was chosen as an important skill in systems analysis, whereas listening skills (another communication skill) form an important part of the combination of business- and systems analysis. Business analysis requires teamwork and leadership - this skill was chosen by all analysts and therefore seems to be a very important skill for all analysts. As worded by one of the interviewees: "Learners should see how important effective communications is to both team and client relationships."

\section{Personal attributes most required for the job}

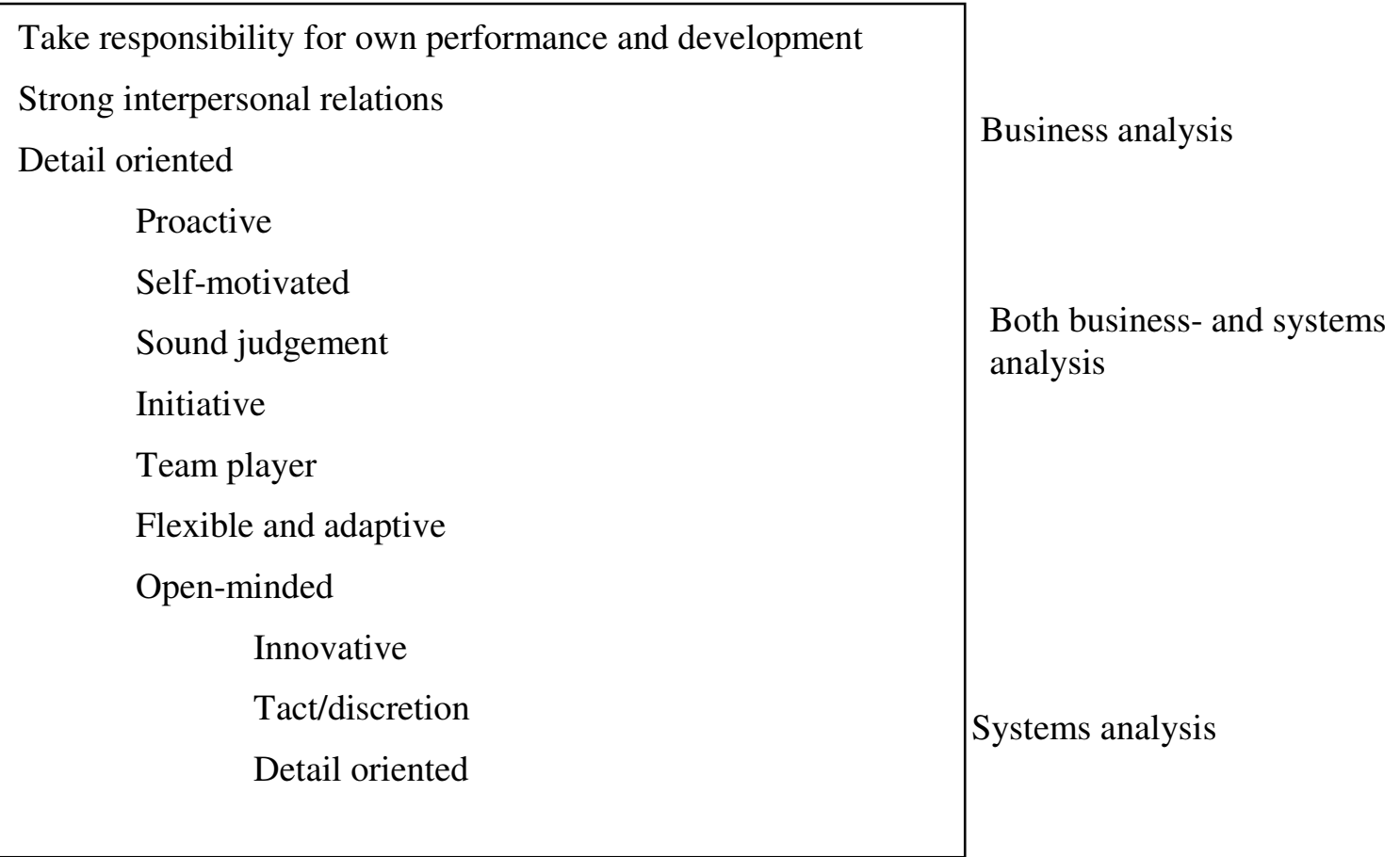

Self-motivation, initiative and being pro-active seem to be important attributes of analysts. One interviewee stated: "Frequent changes in technology will test the adaptability of learners" while another said: "Learners must realize the importance of deadlines." Being a team player is not as important in systems analysis as in business analysis and the combination of the two, whereas open-mindedness, discretion and sound judgement are very important in systems analysis. As 
worded by one interviewee: "You'll be working in cross-functional teams, involved in building consensus and making management decisions. You will need to work with computer scientists, management scientists, information systems analysts, database specialists and administrators, economists, statisticians, accountants, financial managers, financial analysts and market analysts. You should be a good communicator and a team player. Training in communication and negotiation skills is desired."

Business analysis means people have to take responsibility for their own performance and development. This is probably true because the job of the business analyst is not clearly defined and their careers can be "side-tracked" very easily.

\section{Definitions of Business Analysis and Systems Analysis}

Participants were also asked to define business analysis and systems analysis in their own words, to enable the researcher to extract the major elements of the definitions (the phrases that appear most often). The following elements can be added to the list of responsibilities and tasks.

\section{Business analysis:}

Analyse current business practices

Analyse problems

Analyse current business processes

Understand your business environment

\section{Understand and define business requirements}

Analyse business requirements

Identify requirements for improvements

Consult users

Understand and interpret a business need or requirement

\section{Document requirements}

Document and analyse User Requirement Specifications and Business Requirement

Document requirements in a clear and understandable way

\section{Improve business processes}

Provide the most effective process for the user

Find a better way of doing things which eliminate all possible errors

Providing the BEST solution to the user's requirements, having a minimal impacting on time \& money

Analyse \& create a solution that satisfies the users' need/requirement

\section{Link business with IT}

The missing link between business and IT

Provide a common understanding to business people and technical people

Facilitate a compromise between various stakeholders 


\section{Systems analysis}

\section{Technical analysis}

Technical analysis of a system / systems to best optimise and utilise the functionality available to the business' benefit

The technical description of systems needed to enable the business processes described in business analysis

Analyse a computer system and write specifications to enhance the computer system

Analyse current IT Infrastructure to see how it serve the needs of the current business processes

KNOW by hart the IT side of the business

The IT/IS aspect of business analysis

\section{Translate user requirements into technical specification}

Provide technical specifications based on business requirements

Develop quality system documentation to ensure meeting of user needs

Take business case and translate into technical requirement and view how architecture, system software, tables, processes etc will be affected with changes to the core system and evaluate system impact, system response et cetera

\section{Design the technical solution and solve business problems}

Design system solution to business problem - analyse system impact and architecture - develop / implement the system

Find the best technical solution for the business requirement

Converting the 'what' into the 'how' i.e. the physical component

Automating solutions

\section{Testing}

Test the newly engineered version of the program

Conduct Integration Testing User-Acceptance Testing

\section{Training}

Prepare Training Material

Conduct Functional training

Provide support to business during UAT and implementation

\section{Liaison between business and IT people}

Close liaison between business \& development team during development

Act as the link between the systems architect and business in order to understand the requirements and delivering the best solution

\section{Summary and Conclusions}

This research aimed to investigate the gap between the business and the IS/IT function. There are many reasons for the business-IT expectation gap, which were grouped into 25 categories, each containing a number of related issues. Failures of software projects are often a result of short- 
comings on the requirements analysis level. The business analyst and/or systems analyst is there fore an important role-player in bridging the gap. In many cases one person fulfils both these roles. From the professional profile of the analyst, we know that requirements gathering starts with communication between the analyst and client. Given the emphasis on communication problems as one of the major reasons for the business-IT gap, this is not a simple process. The analyst has to interpret the needs of the client and create a reality for a new system. If the requirements are not understood the system will probably fail to fulfil the need of the client.

Analysts are responsible for extracting and documenting user requirements, identifying needs for new information systems and/or -technology, evaluating different solutions, analysing/recording existing business administration processes, determining the impact of new systems on the busi-

ness and activity diagrams. They work with concepts like process flow charts / swim lanes, value chains / end-to-end processes, documentation of each task in detail with data, controls and business rules, entity relationship diagrams / logical data models, functional decomposition and business event data flow diagrams.

Important technical skills required of analysts are programming skills, Hypertext Mark-up language (HTML), Enterprise Resource Planning Software, Java programming, MS Query and MS FrontPage (web page design software). Furthermore they need knowledge of relational databases, data modelling, the Software lifecycle (SDLC), database management, quality management, object oriented analysis/development, Strategic thinking and risk assessment.

The non-technical skills needed by analysts are analytical skills, business sense, detailed problem solving skills, written communication skills, listening skills, leadership skills, facilitation skills, teamwork and the ability to communicate with non-technical users. In terms of personal attributes, analysts have to be proactive, self-motivated, flexible, open-minded and adaptive. They need initiative and sound judgement. Being a team player is also a very important attribute for an analyst. There is a need for a professional body and a body of knowledge for analysts. Such a body of knowledge should clearly define the generic set of analyst skills, as well as the skills distinguishing the two types of analysts from each other.

\section{Future Research}

The second phase of the research will be done during 2004 and 2005 to produce a comprehensive Body of Knowledge for analysis in South Africa. All analysts in the country will be included in the survey. The ABOK will take into consideration the unique characteristics of the South African context and population.

\section{References}

Alexander, S. (1999). What's in a job title? Less and less, some say. InfoWorld, 21 (21).

Meyers, M.D. (2002). Qualitative research in Information Systems. Retrieved February 11, 2002 from http://www2.Auckland.ac.nz/miss/isworld/ 


\section{Appendix 1}

\section{Different Job Titles Associated with the Responsibilities:}

\begin{tabular}{|c|c|}
\hline Business analysis & Both business- and systems analysis \\
\hline Analyst & Analyst \\
\hline Business Analyst & Analyst - Planning and process improve- \\
\hline Business Analyst/Projects\&Problem Resolu- & Business Analyst \\
\hline Business Analyst & Business Design Consultant \\
\hline Director & Business Intelligence Analyst \\
\hline Manager - Business Analysis & Business Process Analyst \\
\hline Manager (Process Management) & Business/systems analyst \\
\hline Manager Process Improvement & Business/technical analyst \\
\hline Manager: Automation\&Manufacturing sys- & Chief systems analyst \\
\hline Product Specialist & Competency Specialist - Analysis \\
\hline Product Specialist (Business Analyst) & Consultant \\
\hline Requirements Engineer & Consultant/Analyst \\
\hline Senior Business analyst & Data \& System Analyst \\
\hline Senior Business Consultant & Deputy Director: Business Analysis \\
\hline Senior Consultant & Deputy Director: Business Systems Analy- \\
\hline \multirow[t]{2}{*}{ Specialist Business Analyst } & Lead Analyst \\
\hline & MIS Analyst \\
\hline System analysis & MU Specialist \\
\hline After Sales Systems Analyst & Owner \\
\hline Business Analyst (Development ) & Planning Business Process Specialist \\
\hline Director - Projects & Product Specialist/Business Analyst \\
\hline Senior Systems Analyst & Senior Business Analyst \\
\hline \multirow[t]{6}{*}{ Systems Analyst } & Senior developer \\
\hline & Solutions Analyst \\
\hline & Both business- and systems analysis \\
\hline & Specialist Software Systems \\
\hline & Systems Analyst \\
\hline & Systems Manager \\
\hline
\end{tabular}




\section{Appendix 2}

\section{Other Responsibilities:}

\begin{tabular}{|rl|}
\hline Both business- and systems analysis: \\
\hline$\circ$ & Gap Analysis between systems \\
\hline$\circ$ & $\begin{array}{l}\text { Integrate business process and system solutions, Develop and/or enhance systems, Pro- } \\
\text { tect intellectual property, Compile / review maintenance specifications, Sign off Change } \\
\text { control and Project gates and closure documents, Logical data store designs, Update } \\
\text { knowledge base, Implement procedures }\end{array}$ \\
\hline$\circ$ & Research \& Development \\
\hline$\circ$ & Programming \\
\hline$\circ$ & $\begin{array}{l}\text { Re-engineering exercises, Integrity checks, Document Business Cases \& BRS, Strategy } \\
\text { designs \& implementation }\end{array}$ \\
\hline$\circ$ & Architecture, Systems integration, Tool-building, Technical training \\
\hline$\circ$ & $\begin{array}{l}\text { Project management - coordinating the IT implementation of system development done, } \\
\text { QA, User sign-off. }\end{array}$ \\
\hline$\circ$ & $\begin{array}{l}\text { Testing \& Support Team Management, Business and Systems Analyst Team Manage- } \\
\text { ment, Business Intelligence, Design and Delivery Member of IT Management Team, }\end{array}$ \\
\hline & Leadership \& Rewards Recognition Team \\
\hline$\circ$ & Ensuring that all linked interfaces are included in required projects etc. \\
\hline \hline$\circ$ & Stakeholder relationship building, Workshop requirements, JAD sessions \\
\hline$\circ$ & Business Process Re-engineering Business Process Improvement \\
\hline &
\end{tabular}

\section{Business analysis:}

- Process Integration, Process Efficiency, Modelling \& Improvement Suggestion, Process Visualisation, Define Change Management Requirements, Compile Logical Data Models, Business Analysis, Training, Linking of System, MIS, Measurement

- Develop Business Cases

$\circ$ Design and analysis of the organisation's business processes and integrating them into a common knowledge base.

- IDEF and IDEF0 diagrams, Database analysis

- Update the Computer and Procedure Manuals

- Test result verification, Problem resolution, Bug finding

- Provide first line user support, as per agreed Service Level Agreements. 
- Compile business case mentoring

- Prepare business process architecture baselines, Manage business architecture projects

\section{Systems analysis:}

○ Implementing ISO 9001:2000 in the organization

- Contract/co-ordinate interfaces, Manage system implementation throughout the SDLC

- Estimate software development in order to produce a quote.

\section{Biography}

Dr. Nina Evans started her career as a Chemical Engineer after graduating from the University of Pretoria in 1982. She registered as a professional engineer (PrEng) and worked as a Research and Development engineer for five years. During this time she completed the Higher Education Diploma (HED), followed by the Diploma in Datametrics, with Computer Science as the major third year subject at the University of South Africa. She then joined the Department of Computer Data Processing at Technikon Pretoria as a lecturer. Two years later she completed a BSc (Hons) degree in Computer Science Cum Laude at the University of Pretoria. She lectured in many aspects of computing, including programming $(\mathrm{C}, \mathrm{C}++$ and Delphi), systems software and operating systems. As Head of the Department of Computer Technology she completed a research project to determine the profile of the Knowledge and Information Technology worker in a changing organisational environment and its impact on the Technikon Information Technology training programs. For this research she received the MTech(Information Technology) degree from Technikon Pretoria . In January 2000 she was awarded a bursary for Masters level study at any Australian university by the former president of South Africa, Mr Nelson Mandela and chose to enrol for an MBA degree at Bond University. She completed the degree in September 2001 with an average of $80 \%$.

In 2003 she completed $\mathrm{PhD}$ degree in Organisational Behaviour from the University of Pretoria. The coursework focused on individual behaviour, group/team behaviour and organisational structures and included subjects like Research Methodology, International Management, Organisational Development, Diversity Management and Virtual Organisations. The title of the dissertation is: "A framework for creating fusion in the business-IT relationship". This study focused on the role-players in the business-IT interface and their impact on the business-IT relationship towards fusion. In January 2004 she received a research grant from the National Research Foundation for further research in this field.

She currently manages the academic programs and personnel of the department Business Applications and IT Management in the faculty of ICT of Tshwane University of Technology. The focus areas of the department are business analysis, project management, business information systems, knowledge management, e-commerce, business management, personal and professional development of IT students/ employees, IT management and strategic management. She also lectures in the fourth year subjects on Business Management, Business Fundamentals, Information and Technology Management and Strategic Information Systems. 